\title{
HARMONIZAÇÃO DO SORRISO COM LAMINADOS CERÂMICOS: RELATO DE CASO
}

\section{Harmonization of smile with ceramic veneers: case report}

Armonización de la sonrisa con laminados cerámicos: informe de caso

Kamila Ramos Tavares Uzêda • Universidade do Estado do Amazonas • Cirurgiãdentista pela UEA / Especialista em Dentística pela Universidade Federal do Rio Grande do Norte/UFRN• E-mail: kamila.uzeda@gmail.com

Isabela Dantas Torres de Araújo • Cirurgiã-dentista pela UFRN / Mestre em Ciências Odontológicas com área de concentração em Clínicas Odontológicas pela UFRN・ E-mail: isabeladta@gmail.com

Victor Jalles de Oliveira • Especialista em Prótese Dentária pela UFRN • E-mail: victorjo86@hotmail.com

Alex José Souza dos Santos • Doutor em Clínica Odontológica com área de concentração em Dentística pela FOP-UNICAMP • Professor Associado do Departamento de Odontologia da UFRN • E-mail: alexjss@yahoo.com

Boniek Castillo Dutra Borges • Doutor em Odontologia com área de concentração em Dentística pela UPE • Professor Adjunto do Departamento de Odontologia da UFRN・E-mail: boniek.castillo@gmail.com

Isauremi Vieira de Assunção • Doutora em Ciências da Saúde pela UFRN • Professora Associada do Departamento de Odontologia da UFRN • E-mail: isauremi@gmail.com

Autora responsável pela correspondência:

Isabela Dantas Torres de Araújo • E-mail: isabeladta@gmail.com 


\section{RESUMO}

Introdução: Os padrões de beleza atuais aumentaram o nível de exigência estética e a busca por sorrisos cada vez mais harmônicos. As facetas cerâmicas destacam-se dentre as opções de tratamentos por associarem estética, longevidade e previsibilidade. Objetivo: Este trabalho objetivou apresentar um caso clínico de substituição de facetas diretas de resina composta por facetas indiretas de porcelana. Descrição do caso: A paciente C.L.M, 25 anos, sexo feminino relatou insatisfação com a estética do seu sorriso, destacando o formato, o tamanho e a cor 1M2 dos elementos dentários 11 e 21. Diante da queixa e da situação clínica observada, propôs-se a confecção de laminados cerâmicos de dissilicato de lítio, mediante a realização prévia de gengivoplastia e de clareamento dentário. Conclusões: Conclui-se que o planejamento cuidadoso, o conhecimento da técnica operatória e a execução adequada do protocolo reabilitador permitem que os laminados cerâmicos reestabeleçam o sorriso de forma estética e funcional.

Palavras-Chave: Estética Dentária. Gengivoplastia. Facetas Dentárias. Clareamento Dentário. Porcelana Dentária.

\section{ABSTRACT}

Introduction: The current beauty standards have increased the level of aesthetic demand and the search for more and more harmonious smiles. The ceramic veneers stand out among the treatment options for combining aesthetics, longevity and predictability. Objective: This study aimed to present a clinical case of substitution of direct resin veneers composed of indirect porcelain veneers. Case description: Patient C.L.M, 25 years old, female, reported dissatisfaction with the aesthetics of her smile, highlighting the shape, size and 1M2 color of dental elements 11 and 21. In view of the complaint and the clinical situation observed, it was proposed to make lithium disilicate ceramic veneers, through previous gingivoplasty and tooth bleaching. Conclusions: It is concluded that the careful planning, the knowledge of the operative technique and the proper execution of the rehabilitation protocol allow the ceramic veneers to reestablish the smile in an aesthetic and functional way.

Keywords: Esthetics, Dental. Gingivoplasty. Dental Veneers. Tooth Bleaching. Dental Porcelain.

\section{ESUMEN}

troducción: los estándares de belleza actuales han aumentado el nivel de demanda tética y la búsqueda de sonrisas cada vez más armoniosas. Las facetas cerámicas se stacan entre las opciones de tratamiento para combinar estética, longevidad y evisibilidad. Objetivo: Este estudio tuvo como objetivo presentar un caso clínico sustitución de carillas de resina directas compuestas de carillas de porcelana irectas. Descripción del caso: La paciente C.L.M, 25 años, mujer, refirió 


\section{ciência
plural}

insatisfacción con la estética de su sonrisa, destacando la forma, tamaño y color 1M2 de los elementos dentales 11 y 21. En vista de la queja y la situación clínica observada, se propuso hacer laminados de cerámica disilicato de litio, mediante reparación gingival previa y blanqueamiento dental. Conclusiones: se concluye que la planificación cuidadosa, el conocimiento de la técnica operativa y la ejecución adecuada del protocolo de rehabilitación permiten a los laminados cerámicos restablecer la sonrisa de una manera estética y funcional.

Palabras clave: Estética Dental. Gingivoplastia. Coronas con Frente Estético. Blanqueamiento de Dientes. Porcelana Dental. 


\section{ciênncia
peral}

\section{Introdução}

A odontologia restauradora vem preconizando a importância de aliar resultados estéticos com procedimentos mais conservadores, evitando desgastes desnecessários da estrutura dentária ${ }^{1,2}$. Há uma grande procura por tratamentos que culminem em soluções estéticas associadas à longevidade e previsibilidade que os materiais e técnicas restauradoras podem oferecer ${ }^{3}$.

A faceta dentária é um procedimento restaurador que pode ser realizado de forma direta, através das resinas compostas, ou de forma indireta através de materiais cerâmicos, como por exemplo a porcelana. Ela recobre a face vestibular do elemento dental e é unida ao elemento dentário por meio de sistemas adesivos. Pode ser confeccionada pela técnica direta ou indireta, e deve proporcionar propriedades ópticas, mecânicas e biológicas semelhantes ao do esmalte natural ${ }^{4,5}$.

As facetas de resina composta podem ser utilizadas adequadamente para modificação de cor, forma, posição e textura dos dentes anteriores ${ }^{6}$. No entanto, esse material é susceptível às alterações de cor, ao desgaste e às fraturas, o que restringe o seu resultado estético ao longo do tempo ${ }^{6-8}$. Para compensar estas limitações, foram então propostas restaurações indiretas, tais como laminados cerâmicos $6,8,9$.

As facetas indiretas destacam-se dentre as diversas opções de tratamentos com finalidades estéticas, pois apesar de requererem algum tipo de desgaste, este quando bem planejado e controlado pode ser mais conservador e efetivo ao se considerar estética e longevidade, além da possibilidade de uma maior conservação das estruturas dentárias quando comparadas as coroas totais ${ }^{1,9-11}$.

A cerâmica é um material de excelência que possui características como biocompatibilidade, resistência, estabilidade de cor, longevidade e ainda apresenta propriedades mecânicas que biomimetizam o esmalte dentário1,4,11-13. Ademais, uando associada às técnicas de preparo minimamente invasivas promove maior eservação de estrutura dental sadia e do periodonto bem como menor risco de ressão à polpa12. 
Este trabalho objetivou apresentar um caso clínico de substituição de facetas diretas de resina composta, com severo manchamento, por facetas indiretas de porcelana.

\section{Descrição do caso}

Paciente C.L.M, 25 anos, gênero feminino, apresentou-se ao curso de Especialização de Dentística da Universidade Federal do Rio Grande do Norte (UFRN) insatisfeita com a estética do seu sorriso, destacando o formato, tamanho e a cor dos elementos 11 e 21, desejando substituir suas restaurações de resina composta por facetas de porcelana. $\mathrm{Na}$ anamnese relatou que fraturou os elementos 11 e 21 quando criança e, desde então, já havia sido realizado substituição dos tratamentos restauradores, devido a estética, por quatro vezes (Figura 1).

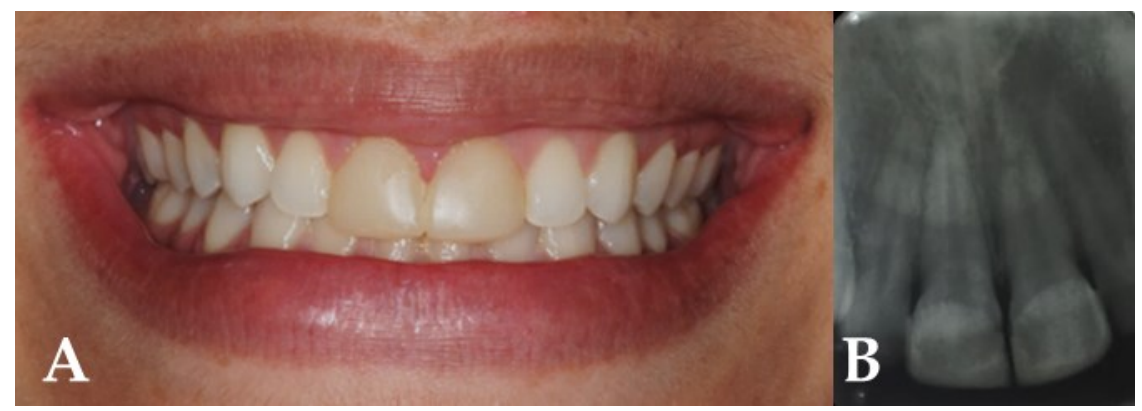

Figura 1. A) Aspecto inicial B) Radiografia inicial. Natal, 2019.

Diante da queixa da paciente e da situação clínica observada, propôs-se a confecção de laminados cerâmicos, mediante a realização prévia de gengivoplastia e clareamento dentário. A plastia foi realizadanos elementos 15 ao 25 (Figura 2).

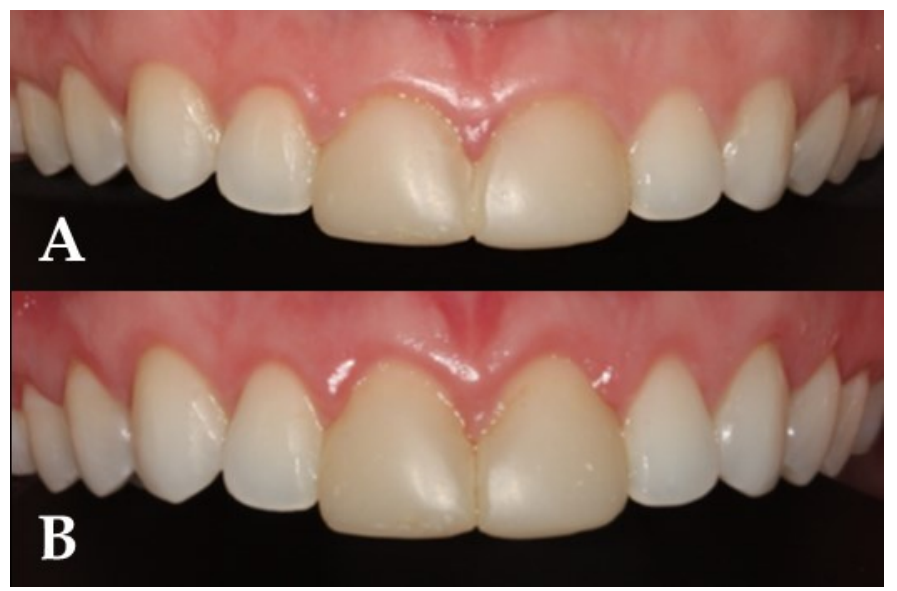

Figura 2. A) Antes da gengivoplastia B) Após a gengivoplastia. Natal, 2019. 
Após a recuperação cirúrgica foi executado o clareamento dentário para dentes vitalizados pela técnica associada, sendo uma sessão da técnica de consultório e 3 semanas de clareamento pela técnica caseira supervisionada. A cor inicial 1M2 foi registrada com a escala VITA 3D MASTER (Vita Toothguide, Zahnfabrik, Bad Säckingen, Alemanha) com profilaxia prévia (Figura 3A).

Para o clareamento de consultório, iniciou-se com uma profilaxia, seguida de isolamento relativo e aplicação da barreira gengival de $2^{\circ}$ pré-molar a $2^{\circ}$ pré-molar, utilizando o Top Dam (FGM, Joinville, SC, Brasil), recobrindo a gengiva marginal e as papilas, ativada por luz LED (Valo, Ultradent Products Inc., South Jordan, UT, USA) por 20 segundos, de três em três dentes. Na sequência, foram feitas duas aplicações de 20 minutos com gel clareador à base de Peróxido de Hidrogênio a 35\% (Whiteness HP, FGM, Joinville, SC, Brasil), e aplicado sobre a superfície vestibular do esmalte com o auxílio de uma seringa hipodérmica de $5 \mathrm{ml}$. Após o término das sessões, aplicou-se um agente dessensibilizante (KF 2\%, FGM, Brasil) por 10 minutos, conforme orientação do fabricante. Os dentes foram lavados adequadamente e a barreira gengival removida.

Após $24 \mathrm{~h}$ do clareamento pela técnica de consultório, a técnica caseira supervisionada foi realizada por 3 semanas utilizando-se o peróxido de hidrogênio a 16\% para uso noturno (tempo mínimo de moldeira de 2,5 horas). Após a conclusão do clareamento foi realizada a tomada de cor final das arcadas, observando redução de nível de saturação para um tom levemente mais claro que 1M1 (Figura 3B). 


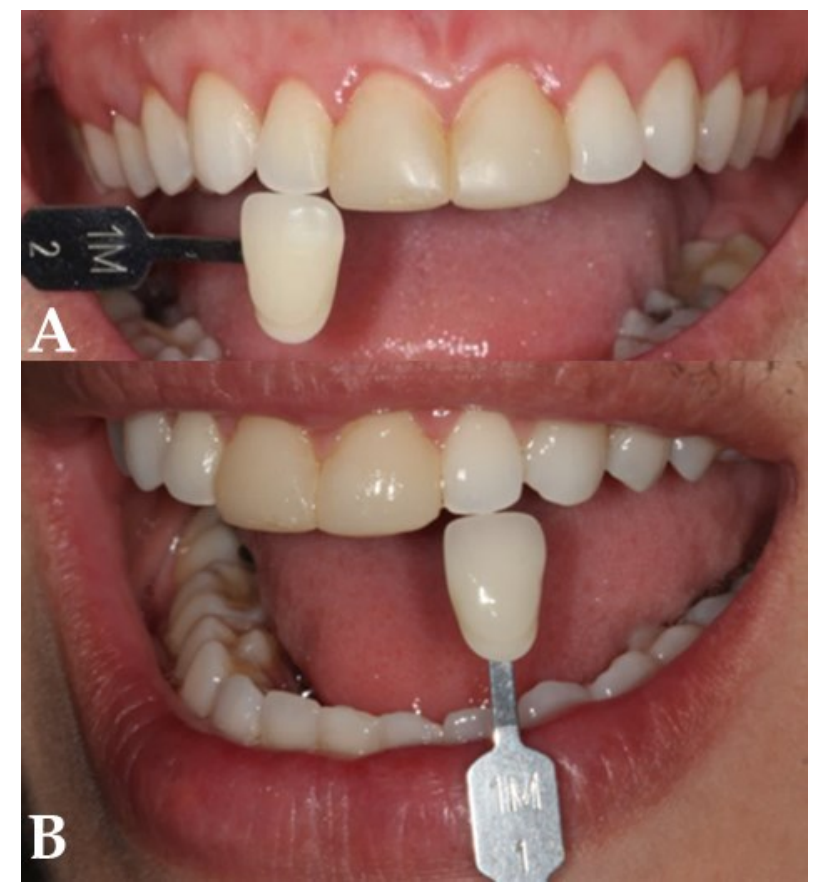

Figura 3. A) Registro da cor inicial. B) Registro da cor final. Natal, 2019.

Após 15 dias de finalizado o clareamento, período necessário para estabilização de cor e ainda liberação de todo oxigênio residual inerente ao gel clareador, a confecção dos preparos para os laminados cerâmicos foi iniciada. Realizou-se anestesia infiltrativa e depois o preparo dos elementos com uma delimitação periférica com ponta diamantada DM6.314.009F (Cepti'om, Alemanha) circundando toda a face vestibular, sem rompimento do contato proximal e sem extensão subgengival. Na sequência, foram realizados sulcos vestibulares no sentido cérvicoincisal com ponta diamantada $\mathrm{n}^{\circ} 2135$ (KG Sorensen, Cotia, SP, Brasil), respeitando as inclinações axiais (cervical, médio e incisal). Em seguida, os sulcos foram unidos com ponta diamantada D10.314.016SF (Cepti'om, Alemanha).

A redução incisal foi realizada com ponta diamantada $\mathrm{n}^{\circ} 3131$ (KG Sorensen, Brasil) em um ângulo de $0^{\circ}$. Foi realizado o término em chanfro, com ângulos internos arredondados, usando-se para isso uma ponta diamantada $n^{\circ} 2135 \mathrm{~F}$ (KG Sorensen, Cotia, SP,Brasil), permitindo uma trajetória correta de inserção dos laminados e um adequado perfil de emergência. Foi necessário o envolvimento das mesiais devido à presença de resina composta nessas faces. O acabamento e polimento do preparo foi realizado com as pontas diamantadas $n^{\circ} 2135 \mathrm{~F}$ e $2135 \mathrm{FF}$ 
(KG Sorensen, Cotia, SP,Brasil) acopladas em um contra-ângulo multiplicador e com borrachas abrasivas (Composite Technique Kit, Shofu, Japão).

Após a conclusão dos preparos, iniciou-se o procedimento de moldagem utilizando-se de um silicone de adição (Express XT, 3M ESPE, Saint Paul, MN, EUA). Para permitir qualidade na moldagem do sulco gengival e do término do preparo, realizou-se o afastamento gengival pela técnica do fio duplo \#00 e \#0 (Ultrapack, Ultradent, USA). O primeiro fio, de menor diâmetro, foi inserido no interior do sulco com espátula fina de ponta arredondada e, em seguida, o segundo fio, de maior diâmetro, foi inserido mais superficialmente.

Com uma moldeira previamente selecionada foi realizada a primeira moldagem com silicone pesado, com auxílio de papel filme de PVC como forma de gerar alívios para o escoamento do material leve. Após a presa do material pesado, o fio superficial foi removido, a moldeira foi carregada com o silicone leve e levada em posição na boca. Posteriormente ao tempo de presa, a moldeira foi removida da boca e o molde foi lavado em água corrente e seco para a verificação da correta reprodução das estruturas. A moldagem foi enviada para o laboratório para confecção dos laminados cerâmicos juntamente com o modelo de gesso feito com as facetas provisórias instaladas, uma vez que a paciente aprovou o formato e tamanho desses provisórios.

Na sequência foram confeccionadas as facetas provisórias com resina composta nanoparticulada (Filtek Z350, 3M ESPE, Saint Paul, MN, EUA), cor A1B, diretamente em boca. Para cimentação, um pequeno ponto da face vestibular foi condicionado com ácido fosfórico a 35\% (Ultra-Etch, Ultradent Products Inc., South Jordan, UT, USA) por 15 segundos, o local foi lavado e seco, para em seguida, receber a aplicação do adesivo (Single Bond Universal, 3M ESPE, Saint Paul, MN, EUA) apenas na área condicionada e este foi fotoativado (Figura 4).Ainda, realizou-se uma moldagem com facetas provisórias a fim de enviar o modelo para o laboratório se basear no mato aprovado pela paciente. 


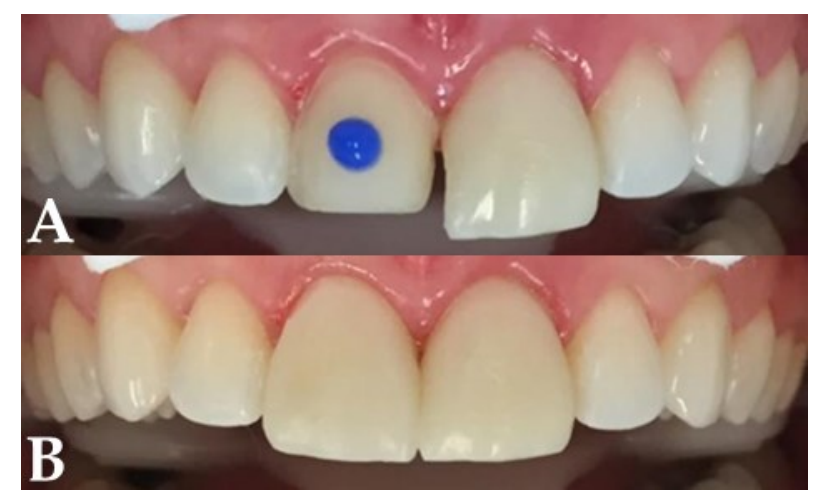

Figura 4. A) Condicionamento com ácido fosfórico 35\% B) Facetas provisórias cimentadas. Natal, 2019.

Na sessão clínica seguinte foi realizada a prova dos laminados cerâmicos a base de dissilicato de lítio (Rosetta HT, cor W3) com a pasta try-in, para análise da cor, forma, adaptação marginal, escolha da cor do cimento, além da aprovação da paciente. Os laminados retornaram ao laboratório para ajustes e em outra sessão foi realizada a cimentação. Para essa etapa, as superfícies internas dos laminados foram condicionadas com ácido fluorídrico a 10\% (Condac Porcelana, FGM, Joinville, SC, Brasil) durante 20 segundos, depois lavadas por 60 segundos e secas com jato de ar. Em seguida aplicou-se uma camada de silano (MonoBond N, Ivoclar Vivadent, Schaan, Liechtenstein) aguardando a evaporação por 1 minuto.

Realizou-se a anestesia infiltrativa, isolamento semi absoluto e afastamento gengival com fio \#000 (Ultrapack, Ultradent, USA) nos elementos 21 e 11. Os preparos receberam profilaxia com pedra pomes (SSWhite Duflex, Juiz de Fora, MG, Brasil) e escova de robinson ultra macia (Ultra Soft, American Burrs, Palhoça, SC, Brasil). Os dentes 12 e 22 foram protegidos com fita de teflon e os preparos foram condicionados com ácido fosfórico a 35\% (Ultra-Etch) por 15 segundos, lavados abundantemente e secos. Então foi aplicada uma camada de adesivo (Single Bond Universal) seguida de fotoativação. $\mathrm{O}$ laminado recebeu uma fina camada de adesivo (Single Bond Universal,) sem fotoativar e o cimento resinoso fotolimerizável (Variolink Esthetic LC, Ivoclar Vivadent, Schaan, Liechtenstein), na cor Warm lecionada previamente, foi aplicado na superfície da cerâmica e levado ao dente no tido inciso-cervical. 
Para fixar e facilitar a remoção do excesso de cimento extravasado realizou-se uma primeira foto-ativação por apenas 3 segundos no centro do laminado. Para isso foi usada a ponteira Pointcure (Ultradent), que realiza a polimerização pontual, acomplada ao aparelho LED (Valo, Ultradent Products Inc., South Jordan, UT, USA) na potência de $1000 \mathrm{~mW} / \mathrm{cm}^{2}$. Com auxílio de pincel e fio dental, removeu-se os excessos de cimento e em seguida foi realizada a foto-ativação por 40 segundos em cada face dos elementos dentários envolvidos. Após isso, o fio afastador foi retirado com sonda exploradora, o cimento remanescente na cervical também foi removido com uma lâmina de bisturi $\mathrm{n}^{\circ} 12$ e nas interproximais com uma tira de lixa para resina composta (3M ESPE, Saint Paul, MN, EUA). Por fim, a oclusão foi verificada em máxima interscupidação habitual, em protusão e lateralidade. Pôde-se observar um resultado esteticamente satisfatório ao comparar-se o antes e depois do caso (Figura 5) além da paciente expressar estar muito satisfeita com o resultado.

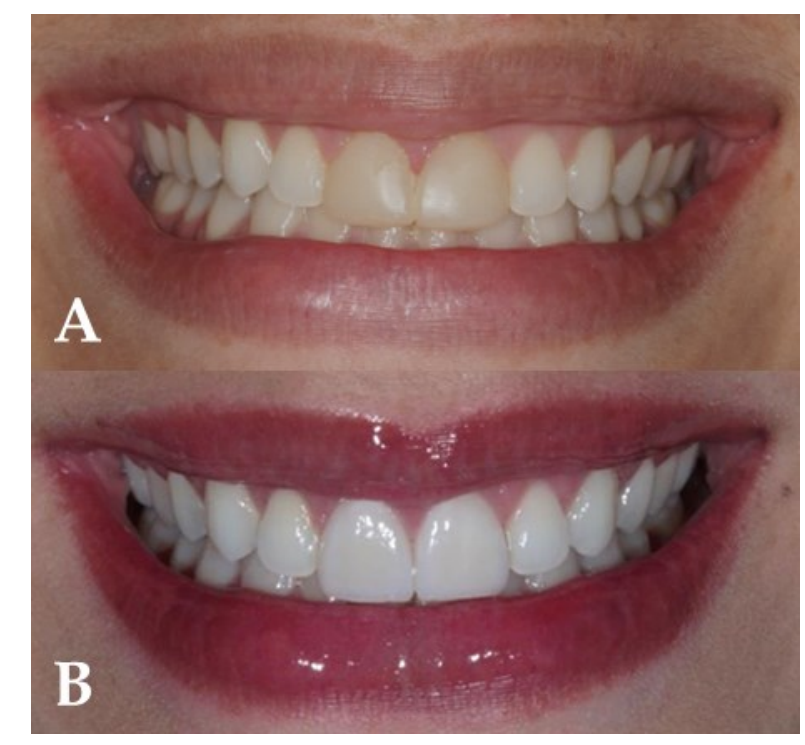

Figura 5.A) Aspecto inicial. B) Aspecto final. Natal, 2019.

\section{Discussão}

Devido aos padrões de beleza atuais os pacientes aumentaram o nível de exigência estética e buscam sorrisos cada vez mais harmônicos. Com a evolução dos nateriais e técnicas odontológicas, as cerâmicas têm se tornado uma ótima opção ara procedimentos restauradores estéticos indiretos ${ }^{10}$. 
No caso clínico relatado, a paciente apresentava facetas diretas de resina composta nos incisivos centrais, apresentando problemas quanto à estabilidade de cor, tamanho e formato após repetidas trocas de restaurações. Dessa forma, a melhor opção para atingir a estética e a expectativa da paciente foi a confecção de facetas de porcelana.

A cerâmica apresenta resistência à compressão, lisura de superfície, resistência ao desgaste/fratura, brilho, características físicas, mecânicas e ópticas semelhantes às do esmalte ${ }^{2}$. Comparando-se facetas confeccionadas em resina composta e cerâmica, as últimas apresentam vantagens como estabilidade de cor por um maior período, menor acúmulo de biofilme bacteriano, maior resistência a fratura e ao desgaste, proporcionando maior longevidade clínica ${ }^{12,13}$.

Em um estudo retrospectivo11, a durabilidade da restauração em cerâmica depois de 7 a 14 anos foi satisfatória com uma aceitação geral para todos os parâmetros no desempenho clínico $(90 \%)$. Houve uma alta taxa de longevidade das facetas aos 7 anos $(97,6 \%)$ e 14 anos $(88,2 \%)$ e a fratura foi a principal causa de falha. Ademais, é importante mostrar que em casos complexos como pacientes com bruxismo, o uso de restaurações em cerâmica também possui uma taxa de sucesso e longevidade alta $(99,6 \%)$, com mínimas complicações clínicas ${ }^{14}$.

O material de escolha para a resolução do caso clínico apresentado foi a cerâmica vítrea à base de dissilicato de lítio. Esta cerâmica apresenta em sua estrutura cristais dispersos de maneira entrelaçada, dificultando a propagação de trincas no seu interior ${ }^{2}$. O tamanho do cristal e a sua disposição favorecem o aumento das propriedades mecânicas da restauração ${ }^{1,2}$. Além disso, o dissilicato de lítio possui um índice de refração de luz semelhante à estrutura dentária, sem interferência significativa da translucidez, o que permite a obtenção de características ópticas finais satisfatórias e naturais².

O dissilicato de lítio é mais seguro do que a cerâmica feldspática uma vez que a diferença entre o estresse desses materiais é significativa $(<10 \%)$, mas próxima o uficiente para antecipar que o estresse crítico do feldspato ocorrerá primeiro, à dida que a força for aplicada. Portanto, pode-se sugerir que, nas mesmas 
condições, uma cerâmica feldspática falharia mais cedo do que em dissilicato de lítio ${ }^{15}$.

Com relação à etapa de moldagem, um afastamento eficaz com o uso do fio retrator é bastante importante para os futuros procedimentos laboratoriais, uma vez que auxilia a visualização dos contornos proximais e vestibular. Outro aspecto relevante é a utilização do silicone de adição, pois, além de proporcionar uma cópia mais detalhada, permite confecção do modelo em até sete dias sem comprometimento da fidelidade do molde e possibilita múltiplos modelos, fator que está relacionado diretamente com o sucesso das etapas laboratoriais ${ }^{1}$.

Durante a prova dos laminados cerâmicos a pasta try-in foi utilizada por permitir previsibilidade da cor final da restauração ${ }^{16,17}$. Para este tipo de restauração, os cimentos de ativação física têm sido considerados uma opção de escolha, pelo fato dos quimicamente ativados e duais apresentarem em sua composição a amina terciária como ativador químico, capaz de provocar alterações de cor no decorrer do tempo ${ }^{1,2,18}$. Em um estudo observou-se alteração de cor após o envelhecimento acelerado de cimentos resinosos com fotoativação diferente, ainda, essa observação foi significante em cimentos duais ${ }^{19}$.

O uso de cimentos de ativação exclusivamente física é essencial para manutenção da estética e estabilidade de cor dos laminados cerâmicos, uma vez que a pequena espessura desses laminados impede mascarar alterações de cor que possam ocorrer nos cimentos ativados quimicamente ou duais ${ }^{1,18}$. É importante considerar a espessura e a cor, tanto do agente cimentante quanto da cerâmica, assim como a cor do substrato, uma vez que todos esses fatores influenciam o resultado estético final20,21. Além disso, espessuras adequadas ajudam a evitar contato prematuro e mudanças na posição final da restauração o que poderia causar fadiga precoce do material ${ }^{22}$.

Os cimentos resinosos fotoativados, geralmente, têm cor muito próxima da trutura dental natural, o que pode dificultar a remoção do excesso de cimento, uma que o cimento pode permanecer nas margens da restauração e assim contribuir o aumento da rugosidade, acúmulo de biofilme e consequente 


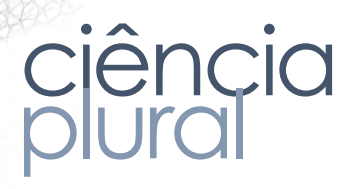

desencadeamento dos processos das doenças cárie e periodontal ${ }^{16}$. Por isso, a remoção do excesso de cimento é extremamente importante para a longevidade do tratamento ${ }^{16}$.

Na cimentação de facetas de porcelana, a remoção sistemática do excesso de cimento resinoso, deve ser feita em fase fluida, preferencialmente, com pincel na face vestibular e nas áreas interproximais, com fio dental, simplificando o acabamento pós-cimentação ${ }^{16}$. Entretanto, fazer essa etapa sem deslocar a peça e remover cimento das margens é uma tarefa complexa. Nesse sentido, no presente trabalho, o laminado cerâmico foi fixado com uso de uma pré-polimerização pontual por 3 segundos na região central da peça. Isso permitiu a remoção do excesso de cimento sem que a peça se deslocasse.

A cimentação das peças cerâmicas com um bom aparelho fotoativador é fundamental, uma vez que a qualidade da luz emitida influenciará diretamente no resultado clínico ${ }^{16,18}$. Os cimentos resinosos são mais afetados pela fotoativação, visto que sempre haverá um material restaurador indireto se sobrepondo à luz e atenuando-a ${ }^{16,23}$. Por este motivo, para os laminados cerâmicos que são mais delgados e a luz consegue ultrapassar mais facilmente, dá-se preferência aos cimentos resinosos fotoativáveis, já que a luz teria bom potencial para atravessar o material e possibilitar uma apropriada ativação ${ }^{23}$.

Um relato de caso, semelhante a este estudo, obteve um excelente resultado estético em incisivo lateral por meio da aplicação de cimento resinoso sem necessidade de desgaste dentário ${ }^{24}$. Ainda, um follow-up de 18 meses concluiu que substituir uma restauração em resina composta por laminados cerâmicos minimamente invasivos pode reabilitar de forma segura e estética os elementos dentários além da oclusão e saúde periodontal25.

Deve ser feito um correto balanço funcional e ajuste oclusal para uma stabilidade adequada após a reabilitação oral de forma a evitar problemas como ratura de borda incisal. É importante considerar a estética em conjunto com os râmetros funcionais do paciente para se obter um resultado de sucesso ${ }^{25}$. 
Por fim, uma vez que há insucesso com um determinado material restaurador como a resina composta, e que a maior falha foi sua instabilidade de cor e manutenção ao longo do tempo, uma ótima alternativa é um material com maior estabilidade de cor e ainda mais resistente, como a cerâmica, ainda mais em casos em que as borda incisais precisam ser aumentadas.

\section{Conclusão}

O planejamento cuidadoso, o conhecimento da técnica operatória e a execução adequada do protocolo reabilitador permitem que os laminados cerâmicos reestabeleçam o sorriso de forma estética e funcional. Vale ressaltar que a relação periodontia e dentística contribuiu para que o caso clínico apresentado obtivesse sucesso e satisfação da paciente.

\section{Referências}

1. Menezes MS, Carvalho ELA, Silva FP, Reis GR, Borges MG. Reabilitação estética do sorriso com laminados cerâmicos: Relato de caso clínico. Rev Odontol Bras Cent 2015;24:37-43. Disponível em: http://files.bvs.br/upload/S/01047914/2015/v23n68/a5432.pdf

2. Zavanelli AC, Caetano JL, da Silva LC, Zavanelli RA. Previsibilidade do tratamento estético com lentes de contato cerâmicas. Arch Heal Investig 2017;6. https://doi.org/10.21270/archi.v6i12.2270.

3. Morita RK, Hayashida MF, Pupo YM, Berger G, Reggiani RD, Betiol EAG. Minimally Invasive Laminate Veneers: Clinical Aspects in Treatment Planning and Cementation Procedures. Case Rep Dent 2016:13. https://doi.org/10.1155/2016/1839793.

4. Okida RC, Vieira WSC, Rahal V, Okida DSS. Lentes de contato: restaurações minimamente invasivas, na solução de problemas estéticos. Rev Odontológica Araçatuba 2016;37:53-9. Disponível em: https://apcdaracatuba.com.br/revista/2016/01/trabalho7.pdf

Fahl Júnior N, Ritter AV. Facetas em resina composta: técnica direta-indireta. ed. Quintessence Publishing Brasil; 2020.

Higashi C, Sakamoto Junior AS, Gomes GM, Calixto AL, Gomes OMM, nes JC. Laminados cerâmicos minimamente invasivos. Full Dent Sci 2012. 
Disponível em: http://studioartdental.com.br/pdf/laminados_ceramicos.pdf

7. Abrantes PS, de Araújo IDT, Borges BCD, de Assunção IV. Restabelecimento da estética do sorriso com laminados cerâmicos: relato de caso. Rev Ciência Plur 2019;5:120-31. https:/ / doi.org/10.21680/2446-7286.2019v5n3ID15736.

8. Oliveira DCRS, Rovaris K, Hass V, Souza-Júnior EJ, Haiter-Neto F, Sinhoreti MAC. Effect of Low Shrinkage Monomers on Physicochemical Properties of Dental Resin Composites. Braz Dent J 2015;26:272-6. https://doi.org/10.1590/01036440201300401.

9. Jordan A. Clinical aspects of porcelain laminate veneers: considerations in treatment planning and preparation design. J Calif Dent Assoc 2015;43:199-202.

10. Annibelli R, Nishimori L, Correa G, Silva C, Progiante P, Marson F. Restabelecimento do sorriso utilizando facetas em dissilicato de lítio. Rev Dent Press 2015;12:34.

11. Arif R, Dennison JB, Garcia D, Yaman P. Retrospective evaluation of the clinical performance and longevity of porcelain laminate veneers 7 to 14 years after cementation. J Prosthet Dent 2019;122:31-7. https://doi.org/10.1016/j.prosdent.2018.09.007.

12. Silva G, Normandes AC, Barros E, Gatti J, Maranhão $K$, Reis AC, et al. Ceramic Laminate Veneers for Reestablishment of Esthetics in Case of Lateral Incisor Agenesis. Case Rep Dent 2018;2018:1-7. https:/ / doi.org/10.1155/2018/4764575.

13. Junior JM, Moretti COI. Reconstrução do sorriso: uma abordagem conservadora através de laminados cerâmicos - relato de caso. Prosthes Lab Sci 2017;6:44-8.

14. Levartovsky S, Pilo R, Shadur A, Matalon S, Winocur E. Complete rehabilitation of patients with bruxism by veneered and non-veneered zirconia restorations with an increased vertical dimension of occlusion: an observational caseseries study. J Prosthodont Res 2019;63:440-6. https:// doi.org/10.1016/j.jpor.2019.02.006.

15. Tribst JPM, Dal Piva AMO, Penteado MM, Borges ALS, Bottino MA. Influence ff ceramic material, thickness of restoration and cement layer on stress distribution occlusal veneers. Braz Oral Res 2018;32:e118. https://doi.org/10.1590/1807107bor-2018.vol32.0118.

Cardoso PDC, Luz CA, Paula A, Magalhães R, Perillo MV, José L, et al. Facetas âmicas: como remover os excessos do cimento resinoso? Clínica - Int J Brazilian nt

2014;10:214-25.

Disponível

em:

s:/ / equipedentistica.com.br/wpdentistica/wp- 
content/uploads/2018/04/Artigo-C.pdf

17. Savaris DI, Vermudt A, Ghizoni JS, Pamato S, Pereira JR. Lentes de contato: Harmonização e estética com preparos conservadores. J Res Dent 2018;6:91. https://doi.org/10.19177/jrd.v6e4201891-97.

18. Novais VR, Raposo LHA, Miranda RR, Lopes CCA, Simamoto Júnior PC, Soares CJ. Degree of conversion and bond strength of resin-cements to feldspathic ceramic using different curing modes. J Appl Oral Sci 2017;25:61-8. https://doi.org/10.1590/1678-77572016-0221.

19. Pissaia JF, Correr GM, Gonzaga CC, da Cunha LF. Influence of shade, curing mode, and aging on the color stability of resin cements. Brazilian J Oral Sci 2015;14:272-5. https:/ / doi.org/10.1590/1677-3225v14n4a04.

20. Vieira AC, Oliveira MCS, Andrade ACV, Sampaio NM, Nascimento LB, Lima JA. Reabilitação Estética e Funcional do Sorriso com Restaurações Cerâmicas de Diferentes Espessuras. Rev Odontológica Araçatuba 2018;39:32-8. Disponível em: https://apcdaracatuba.com.br/revista/2018/12/trabalho6.pdf

21. Rodrigues RB, de Lima E, Roscoe MG, Soares CJ, Cesar PF, Novais VR. Influence of resin cements on color stability of different ceramic systems. Braz Dent J 2017;28:191-5. https:/ / doi.org/10.1590/0103-644020170.

22. Magne P, Cheung R. Numeric simulation of occlusal interferences in molars restored with ultrathin occlusal veneers. J Prosthet Dent 2017;117:132-7. https://doi.org/10.1016/j.prosdent.2016.07.008.

23. Souza Junior E, Pomacóndor-Hernández C, Brandt WC, Sinhoreti MAC. Fotoativação na atualidade: conceitos e técnicas clínicas. Int J Brazilian Dent 2014;10:194-203.

24. Peixoto RVL, Oliveira JR, Ramires MA, Lima CP, Dabul AM, Piemonte MR. Lentes de contato odontológicas - preparo minimamente invasivo: relato de caso. Rev Gestão Saúde 2018;18:44-54. Disponível em: http://www.herrero.com.br/files/revista/filea7cbd6177f915ef5470055bacdbd5212.p df

25. Cunha LF, Prochnow RA, Costacurta AO, Gonzaga CC, Correr GM. Replacement of anterior composite resin restorations using conservative ceramics for occlusal and periodontal rehabilitation: An 18-month clinical follow-up. Case Rep Dent 2016. https://doi.org/10.1155/2016/9728593. 